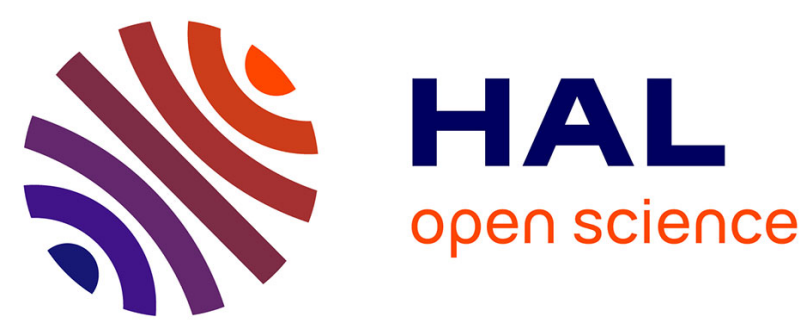

\title{
A comparative study of ceramic nanoparticles synthesized for antibiotic removal: catalysis characterization and photocatalytic performance modeling
}

Aymen Amin Assadi, Oussama Baaloudj, Noureddine Nasrallah, Mohammed Kebir, Lotfi Khezami, Abdeltif Amrane, Aymen Amin Assadi

\section{To cite this version:}

Aymen Amin Assadi, Oussama Baaloudj, Noureddine Nasrallah, Mohammed Kebir, Lotfi Khezami, et al. A comparative study of ceramic nanoparticles synthesized for antibiotic removal: catalysis characterization and photocatalytic performance modeling. Environmental Science and Pollution Research, 2021, 28 (11), pp.13900-13912. 10.1007/s11356-020-11616-z . hal-03037872v2

\section{HAL Id: hal-03037872 \\ https://hal.science/hal-03037872v2}

Submitted on 4 Mar 2021

HAL is a multi-disciplinary open access archive for the deposit and dissemination of scientific research documents, whether they are published or not. The documents may come from teaching and research institutions in France or abroad, or from public or private research centers.
L'archive ouverte pluridisciplinaire HAL, est destinée au dépôt et à la diffusion de documents scientifiques de niveau recherche, publiés ou non, émanant des établissements d'enseignement et de recherche français ou étrangers, des laboratoires publics ou privés. 


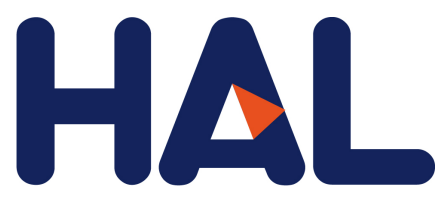

archives-ouvertes

\section{A comparative study of ceramic nanoparticles synthesized for antibiotic removal: catalysis characterization and photocatalytic performance modeling}

Oussama Baaloudj, Noureddine Nasrallah, Mohammed Kebir, Lotfi Khezami, Abdeltif Amrane, Aymen Amin Assadi

\section{To cite this version:}

Oussama Baaloudj, Noureddine Nasrallah, Mohammed Kebir, Lotfi Khezami, Abdeltif Amrane, et al.. A comparative study of ceramic nanoparticles synthesized for antibiotic removal: catalysis characterization and photocatalytic performance modeling. Environmental Science and Pollution Research, Springer Verlag, 2020, 10.1007/s11356-020-11616-z . hal-03037872

\section{HAL Id: hal-03037872 \\ https://hal.archives-ouvertes.fr/hal-03037872}

Submitted on 18 Dec 2020

HAL is a multi-disciplinary open access archive for the deposit and dissemination of scientific research documents, whether they are published or not. The documents may come from teaching and research institutions in France or abroad, or from public or private research centers.
L'archive ouverte pluridisciplinaire HAL, est destinée au dépôt et à la diffusion de documents scientifiques de niveau recherche, publiés ou non, émanant des établissements d'enseignement et de recherche français ou étrangers, des laboratoires publics ou privés. 


\section{A comparative study of ceramics nanoparticles synthesized for} antibiotic removal: Catalysis characterization and photocatalytic performances modeling

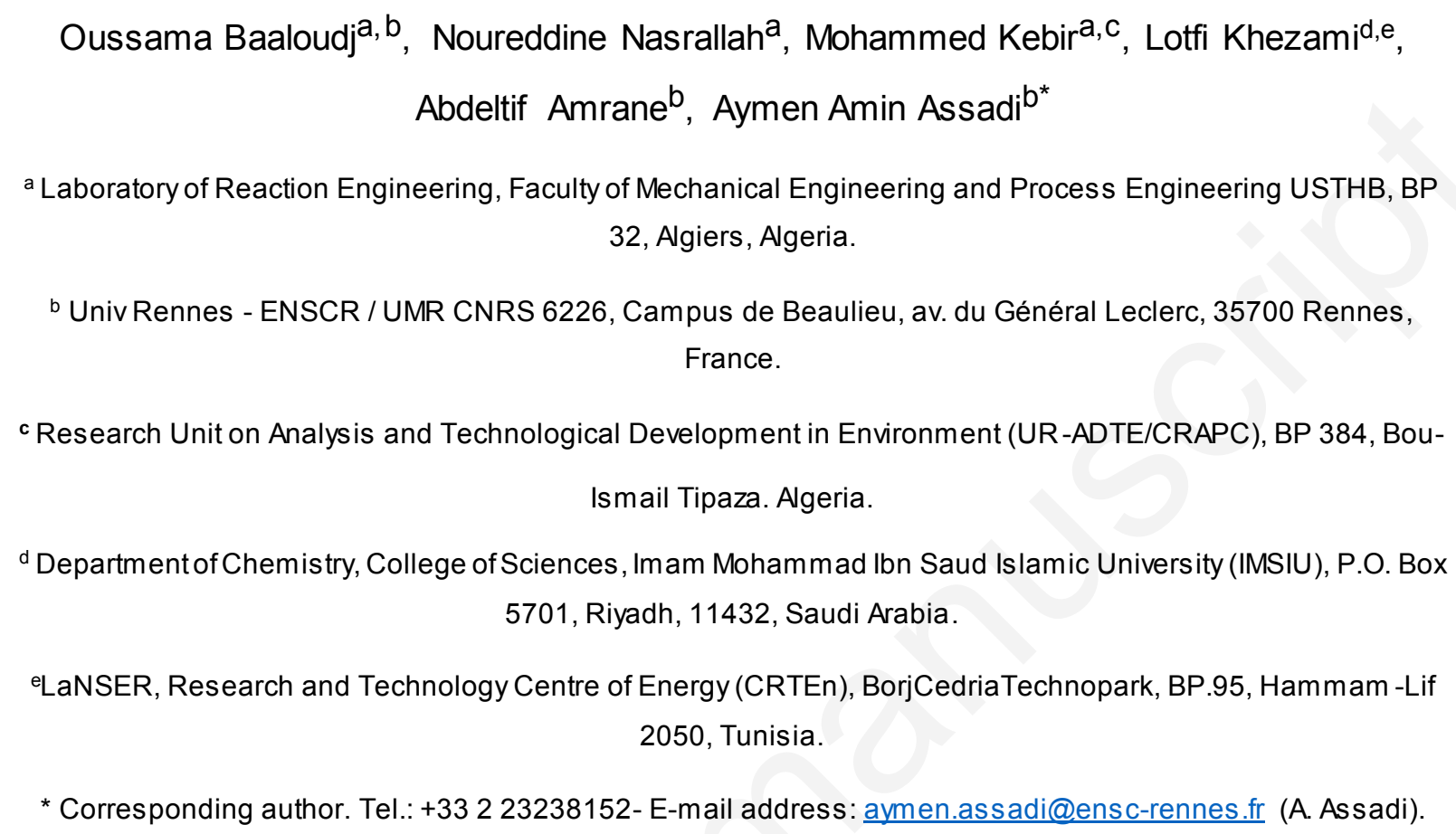

\section{Abstract}

The heterogeneous photocatalysis process has been known to provide significant levels of degradation and mineralization of emerging contaminants including antibiotics. For that, nanoparticles $\mathrm{CuCr}_{2} \mathrm{O}_{4}$ (CCO) ceramics were successfully prepared via sol-gel (SG) and co-precipitation (CP) methods to obtain spinel with desired structural features and properties and also to improve the photocatalytic performances. The CCO crystallite phase was produced at $750{ }^{\circ} \mathrm{C}$ all ceramics, disregarding the synthesis route. CCO physical and chemical properties were checked by X-ray diffraction (XRD) with Rietveld refinement, Brunauer Emmett Teller (BET), Fourier Transform Infrared Spectroscopy (FT-IR), Scanning Electron Microscope (SEM), Transmission Electron Microscope (TEM) and Diffuse Reflectance Solid (DRS). The XRD patterns demonstrated that the synthesized catalysts displayed a small crystallite size between 17.45 and $26.24 \mathrm{~nm}$ for SG and 20.97 to $36.86 \mathrm{~nm}$ for the CCOCP samples. The observation by SEM and TEM of the nanopowders showed a typical morphology with comparable particle sizes for both synthesized routes (20-30 nm). SG agglomeration rates were higher, and particles 
stick together more efficiently considering the $\mathrm{CP}$ method, while the $\mathrm{CCO} \mathrm{CP}$ method led to a more significant porosity.

Their photocatalytic and adsorption performances were examined for Cefaclor (CFC) removal chosen as a target pharmaceutical contaminant in water. The results obtained by the methods differed since nanoparticles prepared by SG led to high photocatalytic activity. In contrast, a high CFC adsorption was observed for those prepared via the CP method, and that agreed with the findings of the characterization analysis. The Kinetics of the adsorption process was found to follow the pseudosecond-order rate law. In contrast, the data of the photodegradation process were further found to comply with the Lagergren kinetic law. Nevertheless, the global reaction rate is probably controlled by the intra-particular diffusion of CFC, regardless of the elimination process.

Keywords: Ceramics nanoparticles, Co-precipitation, Sol-gel processes, Photocatalysis, Adsorption, Kinetic modeling.

\section{Introduction}

Water is definitely our planet's most important natural resource, and it is necessary for all species in our lives. Approximately $71 \%$ of the surface of the earth is wrapped by water, while the oceans occupy about $96.5 \%$ of the water resources (Kümmerer 2009). In the context of icecaps and frozen seas, freshwater constitutes only $2.5 \%$ of the polar premises and rivers, lakes and reservoirs only $0.3 \%$ of the global water resources. Despite the lack of fresh water on earth, it is constantly contaminated with various chemical contaminants such as drugs (Kaczala and E. Blum 2015).

Various medicinal compounds have sullied the aqueous environment in recent years, including antibiotics that need special attention because of their large use in human and veterinary medicine (Lalouckova and Skrivanova 2019), as well as in improving feed quality and growth levels in the livestock and poultry industries. in addition, antibiotics are the main concern of researchers all over the world if compared to the other categories of pharmaceutical products because of their increasing aquatic toxicity and nonbiodegradabilty in the environment (Mostafaloo et al. 2019; Aissani et al. 2020). Generally, antibiotics are present at amounts ranging from $\mathrm{ng} / \mathrm{L}$ to $\mu \mathrm{g} / \mathrm{L}$ in treated wastewater (Ikhlef-Taguelmimt et al. 2020; Kadji et al. 
2020). Even at very low amounts, the existence of these substances in water resources, enhances bacterial resistance (Shooshtari and Ghazi 2017).

A target antibiotic example is Cefaclor (CFC) belonging to the beta-lactam group, second-generation cephalosporin with antibacterial activity. Cefaclor is $(6 R, 7 R)-7-$ [[(2R)-2-amino-2-phenylacetyl]amino]-3-chloro-8-oxo-5-thia-1 azabicyclo [4.2.0] oct2-ene-2-carboxylic acid with molecular formula $\mathrm{C}_{15} \mathrm{H}_{14} \mathrm{ClN}_{3} \mathrm{O}_{4} \mathrm{~S}$. Also, it is a cephalosporin bearing chloro and (R)-2-amino-2-phenylacetamido groups at positions 3 and 7, respectively; the above described molecular structure is displayed in Figure S.1. It has a role as an antibacterial and allergen drugs. To our knowledge, no study has been made yet concerning the photocatalyst degradation of cefaclor.

Conventional methods cannot effectively eliminate antibiotic residues due to antibacterial nature (Chen and Huang 2010; Li and Zhang 2010; Gao et al. 2012). In this respect, Advanced Oxidation Processes (AOPs) have proven to be a suitable alternative for the rapid destruction of recalcitrant and non-biodegradable compounds in contaminated waters (Lou et al. 2017; Aboudalle et al. 2018; Kamagate et al. 2018; Yahiaoui et al. 2018; Kadji et al. 2020). The heterogeneous photocatalysis process in particular has been successfully used to degrade different types of pharmaceutical drugs and organic compounds (Zhu et al. 2013; Aissani et al. 2018, 2020; Hou et al. 2019; Ikhlef-Taguelmimt et al. 2020; Shan et al. 2020). our previous study showed that $\mathrm{CuCr}_{2} \mathrm{O}_{4}$ (CCO) photocatalyst had a good photocatalytic reduction of $\mathrm{Cr}(\mathrm{VI})$ (Lahmar et al. 2012). Also, CCO has been shown a significant degradation activity for removal of organic and antibiotics compounds (Akhundi and HabibiYangjeh 2017; Hariganesh et al. 2020). For that, CCO was considered and It was synthesized by different routes.

There is a considerable amount of research concentrating on the preparation methods to enhance the photo-catalytical properties as they have been found to have a strong effect on the semiconductor's crystallinity (Santhanam and Rambabu 2010; Kafshgari et al. 2019). The facile method for preparing CCO ceramic involves mixing copper nitrate and chromium nitrate in a 1:2 molar ratio and then calcining at $750 \mathrm{C}^{\circ}$ for 6 hours (Acharyya et al. 2015). Wet chemical methods like sol-gel (Geng et al. 2012), co-precipitation ( $\mathrm{Hu}$ et al. 2011) and hydrothermal (Mobini et al. 2017) methods are auspicious routes for yielding high purity single-phase $\mathrm{CCO}$ at approximately low temperatures, although certain inconveniences exist. For example, 
hydrothermal synthesis needs the usage of an autoclave with pressures of about 70$175 \mathrm{MPa}$ (Ramanujam et al. 2014), whilst synthesized combustion powders lead to chemical inhomogeneity and particles agglomeration because of strong local heating (Devi et al. 2002; Ramanujam et al. 2014; Das et al. 2018). Nevertheless, the synthesis of sol-gel and co-precipitation may be inexpensive methods and more expected to produce homogenous CCO nanopowders. In addition, it has already shown that these methods have a positive impact on semiconductor efficiency (Paul et al. 2015; Peymanfar and Ramezanalizadeh 2018).

Thus, the ceramic $\mathrm{CuCr}_{2} \mathrm{O}_{4}$ has been synthesized by two different synthesis methods, using the sol-gel and co-precipitation methods. The obtained solid powders were characterized by different analyses, and the properties of the two obtained powders were explored and compared. The final aspect of this study was the examination and modeling of the photodegradation and the adsorption performances of $\mathrm{CFC}$ upon visible light irradiation using $\mathrm{CCO}$ as a semiconductor.

\section{Material and methods}

\subsection{Chemicals}

Copper nitrate trihydrate $\left[\mathrm{Cu}\left(\mathrm{NO}_{3}\right)_{2} \cdot 3 \mathrm{H}_{2} \mathrm{O}\right]$ (98\% Fluka), chromium nitrate nonahydrate $\left[\mathrm{Cr}\left(\mathrm{NO}_{3}\right)_{3} \cdot 9 \mathrm{H}_{2} \mathrm{O}\right]\left(98 \%\right.$ Biochem), Cefaclor Monohydrate $\mathrm{C}_{15} \mathrm{H}_{14} \mathrm{ClN}_{3} \mathrm{O}_{4} \mathrm{~S}$ and Polyvinylpyrrolidone (PVP) K30, procured from a pharmaceutical company Pharmalliance in Algeria, ethanol from Biochem, and $\mathrm{NaOH}, \mathrm{HCl}$, nitric acid from Sigma Aldrich, were utilized in the research. All used chemicals are of analytical grade.

\subsection{Synthesis of $\mathrm{CuCr}_{2} \mathrm{O}_{4}$ via sol-gel method}

CCO was synthesized via the aqueous PVP sol-gel method (Figure S.2 a). The gel was prepared using stoichiometric amounts (1:2 ratio) of copper nitrate trihydrate $\left[\mathrm{Cu}\left(\mathrm{NO}_{3}\right)_{2} \cdot 3 \mathrm{H}_{2} \mathrm{O}\right]$ and chromium nitrate nonahydrate $\left[\mathrm{Cr}\left(\mathrm{NO}_{3}\right)_{3} \cdot 9 \mathrm{H}_{2} \mathrm{O}\right]$ respectively, which were dissolved in ethanol separately by using a magnetic stirrer, an excess of $5 \%$ citric acid was added in the solutions. After a total solubility, the two solutions were mixed and were placed on a hot plate at $50{ }^{\circ} \mathrm{C}$ for $1 \mathrm{~h}$. Then, Polyvinylpyrrolidone (PVP K30) as a complexing agent (15\% w/w (Giannopoulou et al. 2015)) was dissolved in $50 \mathrm{ml}$ water and added dropwise to the reaction medium. Subsequently, to the concentration of the solutions by evaporation at $80^{\circ} \mathrm{C}$ for $20 \mathrm{hrs}$ 
under stirring, the mixed solution turned into a black gel. The obtained gel was dried at $200{ }^{\circ} \mathrm{C}$ for $6 \mathrm{~h}$ and an auto combustion reaction took place giving a precursor powder (Xerogel).

The amorphous powder was ground and subjected to calcination at $700^{\circ} \mathrm{C}$ in an air atmosphere for 6 hours (Mobini et al. 2017). The synthesized sample was annealed to improve the degree of crystallinity as well as to eliminate any carbonaceous residue left after the combustion reaction. Then, the resulting nanopowder was subjected to phase identification, comparative and application studies.

\subsection{Synthesis of $\mathrm{CuCr}_{2} \mathrm{O}_{4}$ via co-precipitation method}

CCO was prepared by chemical co-precipitation (Figure S.2 b). Stoichiometric amounts $1: 2$ of copper nitrate trihydrate $\left[\mathrm{Cu}\left(\mathrm{NO}_{3}\right)_{2} \cdot 3 \mathrm{H}_{2} \mathrm{O}\right]$ and chromium nitrate nonahydrate $\left[\mathrm{Cr}\left(\mathrm{NO}_{3}\right)_{3} \cdot 9 \mathrm{H}_{2} \mathrm{O}\right]$ were totally dissolved in an aqueous solution, then $5 \%$ of concentrated $\mathrm{HNO}_{3}$ was added under continuous magnetic stirring. $\mathrm{NaOH} 6 \mathrm{M}$ solution was dropped into the bleu mixture with vigorous stirring to keep the $\mathrm{pH}$ in the range (9-10). A black to bluish precipitate was produced immediately confirming the formation of CCO spinel. Consequently, the precipitate was filtered and washed several times repeatedly with distilled water then dried at $120{ }^{\circ} \mathrm{C}$ for $24 \mathrm{~h}$ in an autoclave; then, the precursor powder was ground to a fine powder.

The obtained powder was annealed at $700^{\circ} \mathrm{C}$ under air for 6 hours to remove possible residual organic matter and to obtain a single crystalline phase (Mobini et al. 2017). Moreover, the as-synthesized sample was subjected to phase identification, comparative and application studies.

\subsection{Photocatalyst characterization}

The phase analysis was investigated by $X$-ray diffractometer $(X R D)$ in the range from $5^{\circ}$ to $80^{\circ}$. with Phillips PW 1730 , X-ray diffractometer using monochromatized Cu K radiation $(\lambda=0.15417 \mathrm{~nm})$. The surface morphology of the sample SEM was observed by using Scanning Electron Microscope Brilliance 180P. as well as transmission electron microscope (TEM JEOL-24011BU) considered to take images of the nanostructures. ATR-FTIR spectra were achieved in the range of 400-4000 $\mathrm{cm}^{-1}$ by using an Alpha Bruker spectrometer. UV-visible diffuse reflectance spectrum (DRS) of the sample was measured with dry pressed disk samples through Cary 5000 UV-vis equipped with the integration sphere. 


\subsection{Adsorption procedure}

Cefaclor antibiotic (CFC) was chosen as a pharmaceutical contaminant model to investigate the adsorption performance of the two samples of CCO. The adsorption of CFC was conducted in batch mode by mixing $0.1 \mathrm{~g}$ of catalyst and solution CCF $(100 \mathrm{~mL})$ with an initial concentration of $10 \mathrm{mg} / \mathrm{L}$. The solution was continuously stirred in the dark at a fixed ambient temperature in a closed reactor for 2 hours. At a regular interval of time, $2 \mathrm{~mL}$ of sample was taken and separated by centrifugation at the speed of $5,000 \mathrm{rpm}$ for $10 \mathrm{~min}$. the aliquot concentration was directly analyzed by UV-Visible spectrometry (OPTIZEN, UV-3220UV) at the maximum absorption wavelength of CFC (264 nm) (Fig. S.3). It should be mentioned that the small positive error of UV-Visible spectrometry in comparison with HPLC was considered insignificant and hence ignored. The experiments were done in triplicate under the same conditions. The adsorption rate of CFC was calculated using the following equation (1):

$$
\text { Adsorption }(t) \%=\frac{\left(C_{O}-C(t)\right)}{C_{O}} \times 100
$$

Where Co $\left(\mathrm{mg}^{\mathrm{L}} \mathrm{L}^{-1}\right)$ is the initial concentration of CFC and $\mathrm{C}(t)\left(\mathrm{mg} \cdot \mathrm{L}^{-1}\right)$ is the concentration of CFC at a given time $t(\mathrm{~min})$.

\subsection{Photocatalytic procedure}

The photocatalytic degradation of CFC was conducted using $0.1 \mathrm{~g}$ of $\mathrm{CCO}$ added to $100 \mathrm{~mL}$ of CFC solution with $20 \mathrm{mg} / \mathrm{L}$ initial concentration in a natural $\mathrm{pH}$ 6 , as those are the optimal conditions for the observation of the photodegradation process as $10 \mathrm{mg} / \mathrm{L}$ initial concentration of CFC was partially removed by adsorption. The suspension was continuously stirred for $120 \mathrm{~min}$ in dark condition in a closed reactor to reach the balance of adsorption and desorption before switch on the visible light. A tungsten lamp (200 W) was used as a visible light source. With a cooling system, the temperature of the solution during all the photocatalytic experiments was kept constant. Aliquot of $3 \mathrm{~mL}$ was withdrawn from the mixture at a predetermined time centrifuged before further analysis. The experiments were performed in triplicate under the same conditions for adsorption and photodegradation experiments. The photodegradation rate of CFC was calculated using the following equation (2): 


$$
\text { Photodegradation }(t) \%=\frac{\left(C_{A d}-C(t)\right)}{C_{A d}} \times 100
$$

Where $\mathrm{Cad}_{\mathrm{ad}}(\mathrm{mg} / \mathrm{L})$ is the initial concentration of CFC after adsorption and C $(t)(\mathrm{mg} / \mathrm{L})$ is the concentration of CFC at time $t(\mathrm{~min})$.

\subsection{Adsorption and photodegradation kinetics study}

Adsorption Kinetics and mechanism study are essential in the treatment of aqueous wastewater as it provides valuable information on of adsorption process. Adsorption kinetics experimental data is generally presented by a pseudo-first- or pseudo-second-order law. Equation (3) represents a pseudo-first-order model of Lagergren (S Lagergren, S LAGERGREN, S.Y. Lagergren, SY Lagergren 1898) with a rate constant $k_{1}\left(\mathrm{~min}^{-1}\right)$ and $q_{e}$ the maximum amount of CFC adsorbed at equilibrium. The plot of $\ln \left(q_{e}-q_{t}\right)$ against $t$ permit the determination of $k_{1}$ and $q_{e}$, respectively.

$$
\operatorname{Ln}\left(q_{e}-q_{t}\right)=\operatorname{Ln}\left(q_{e}\right)-k_{1} \cdot t
$$

A pseudo-second-order law can be represented by equation (4), where $k 2$ stands for the pseudo-second-order rate constant $\mathrm{g}(\mathrm{mg} \cdot \mathrm{min})^{-1}$ (Y.S. Ho 1998, 1999). Both parameters $q_{e}$ and $k 2$ can be obtained from the slope and intercept of $t / q t$ versus $t$ graph.

$$
\frac{t}{q_{t}}=\frac{1}{k_{2} \cdot q_{e}^{2}}+\frac{t}{q_{e}}
$$

The uptake and photodegradation of CFC can be controlled by either the mass transfer through the boundary film of liquid or by the intra-particular mass transfer.

The linearized equation of mass transfer kinetic model proposed by Ketcha Mbadcam et al (Mbadcam et al. 2011), is expressed as follows:

$$
\operatorname{Ln}\left(C_{0}-C_{t}\right)=\operatorname{Ln}(D)+k_{0} \cdot t
$$

where $C_{0}$ and $C_{t}$ are respectively the initial concentration and concentration of solute (mg.L-1) at an instant $t(\mathrm{~min}), D$ is the mass transfer constant and $k o\left(\mathrm{~min}^{-1}\right)$ the adsorption constant. CFC may be conveyed from the solution to the solid particles by the intra-particle diffusion/transport process. Sometimes, such a mechanism model is a rate-limiting step in the adsorption or photodegradation process. The probability of intra-particular diffusion is examined through the Weber and Morris diffusion model (El-Sikaily et al. 2007; Hameed et al. 2009): 


$$
q_{t}=k_{d i f} \cdot t^{1 / 2}+C
$$

where the intercept $\mathrm{C}$ provides information about the thickness of the boundary layer. The intra-particle diffusion constant, kdif values (in $\mathrm{mg}^{-1} \cdot \mathrm{min}^{1 / 2}$ ), for the tested adsorbent are obtained from the slopes of the graphs (Figures 15 and 16) as illustrated in Table 3 and 4 . The validity of these models is thereafter discussed based on the regression coefficient $r^{2}$.

\section{Results and discussion}

\subsection{CCO Characterization results}

In order to investigate the single phase of $\mathrm{CCO}$ in the samples, X-ray diffraction (XRD) patterns after calcination were elucidated in figure 1. In both methods, almost the same single phase of $\mathrm{CCO}$ without impurity was formed. The phase of the $\mathrm{CCO}$ could be indexed to the typical diffraction lines of the bulk, all the peaks were assigned to the single-phase spinel of $\mathrm{CuCr}_{2} \mathrm{O}_{4}$ in good accordance with the standard card (JCPDS 98-005-9266) (Villars and Cenzual; Dollase and O'Neill 1997). The only difference observed was the crystallite size which was calculated with the following Debey-Scherer formula Eq. (3) and which could be due to the high intensity of all peaks. The crystalline size for the sol-gel method was found to be in the range of 17.45 to $26.24 \mathrm{~nm}$ and for co-precipitation, it was in the range of 20.97 to $36.86 \mathrm{~nm}$.

$$
D=\frac{K \lambda}{\beta \cos (\theta)}
$$

where $D$ is the average crystallite size of the phase under investigation in nanometers, $\mathrm{K}$ is the Scherrer constant, $\lambda$ is the wavelength of $\mathrm{X}$-ray beam used, $\beta$ is the full width at half maxima (FWHM) in radians and $\theta$ is the Braggs angle.

The X-ray density was estimated from the standard relation shown in equation (4) (Kenfoud et al. 2020).

$$
\rho=\frac{Z M}{N_{A} V}
$$

Where $N_{A}$ is Avogadro's number $\left(6.02 \times 10^{23} \mathrm{~mol}^{-1}\right), M$ is the molecular weight of CCO $\left(231.535 \mathrm{~g} \cdot \mathrm{mol}^{-1}\right), Z$ is the number of formula unit present in a unit cell $(Z=4)$ 
and $V$ is the volume of the unit cell $\left(283.05 \times 10^{6} \mathrm{pm}^{3}\right)$ The X-ray density for both methods was found to be $5,43 \mathrm{~g} \cdot \mathrm{cm}^{-3}$.

Significant parameters including particle size, shape and density are associated with the specific surface area (SSA) measurements $\left(\mathrm{m}^{2} \cdot \mathrm{g}^{-1}\right)$. Using the Brunauer-EmmettTeller (BET) equation (5) (Bykkam et al. 2015), the specific surface area of CCO nanoparticle was measured.

$$
S=\frac{6 \times 10^{3}}{D p \times \rho}
$$

where $D p$ is the size of the particles, $S$ is the specific surface area, and $\rho$ is the $\mathrm{X}$-ray

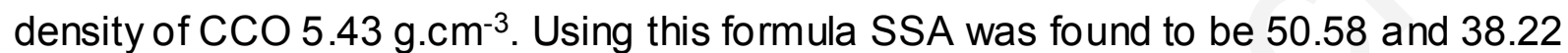
$\mathrm{m}^{2} \cdot \mathrm{g}^{-1}$ for the nanoparticles obtained by the sol-gel and the co-precipitation methods, respectively. Consequently, very fine nanoparticles were obtained by the sol-gel method, the smaller the particle size of the catalyst, the bigger the particular surface area. A high catalyst surface area may result in better catalytic activity.

Fig. 1 XRD diffractogram of CCO (a) co-precipitation (b) sol-gel.

For the structural investigation of $\mathrm{CCO}$, the XRD of the sol-gel was chosen and a Rietveld refinement method supplied by Maud software (version 2.93) was used. The experimental points are given as $\operatorname{dot}($.) and theoretical data determined by Maud are shown as a red line (Fig. 2). The difference between theoretical and experimental data is shown as the bottom line. The vertical lines reflect the approved Bragg's peaks. The results (Fig. 2) showed a strong matching with the findings calculated by the technique Rietveld and those observed in the experimental X-ray diffraction patterns.

The refined values represented an orthorhombic structure (space group Fddd:2) which is different from the database. In comparison with other known methods of structural properties, the Rietveld refinement results gave identical results (YE, Zuo-Guang; Dollase and O'Neill 1997). The refinement was done by calculating the reliability factors such as profile $R p$, expected profile $R_{\text {exp }}$, and weighted profile $R_{w p}$ and Sig (GOF) which is the strength of the ratio of $R_{w p}$ to $R_{\exp }$ (Akhtar et al. 2019). For refined structural parameters, GOF must be close to 1 . Rietveld refined parameters (R-factors) with the cell parameters $(a, b, c)$ and atomic position $(x, y, z)$ of Rietveld are described in Table 1. The inset in Figure 2 showed the schematic 
representation of the CCO structure by Vesta (version 3.4.0) using the parameters of the table.

Fig. 2 Reitveld refined XRD diffractograms. Inset: the structural representation of CCO.

Table. 1 Rietveld refined parameters from MAUD software.

Phase crystallite of $\mathrm{CuCr}_{2} \mathrm{O}_{4}$ can be confirmed by $\mathrm{FTIR}$ analysis and support the conclusion drawn by XRD data shown in Fig. 3. One can see that both methods showed the same FTIR spectrum with the absence of any vibration band attributable to carbonates. The synthesized CCO showed broad absorption bands arising from $\mathrm{O}-\mathrm{H}$ stretching and bending vibration of water at $3000 \mathrm{~cm}^{-1}$ (Geng et al. 2012). The same three strong absorption bands observed in both sol-gel and co-precipitation samples in the region of $600-480 \mathrm{~cm}^{-1}$ belonged to the typical metal-oxygen (M-O) stretching vibrations (Geng et al. 2012; Mobini et al. 2017; Ramezanalizadeh et al. 2019). The two peaks at $599.79 \mathrm{~cm}^{-1}$ and $552.35 \mathrm{~cm}^{-1}$ confirmed the formation of spinel copper chromite powder, which arose due to the stretching vibration of $\mathrm{Cr}^{3+}$ $\mathrm{O}^{2-}$ at tetrahedral and octahedral sites coordination existence (Mobini et al. 2017). Also, the absorption peak at $488.61 \mathrm{~cm}^{-1}$ corresponds to the metal-oxygen (Cu-O) vibration bond in the complex (Ramezanalizadeh et al. 2019). Moreover, the absorption bands appeared at $552.35 \mathrm{~cm}^{-1}$. could also be related to the stretching vibrations of the $\mathrm{Cr}-\mathrm{O}-\mathrm{Cu}$ structure (Mobini et al. 2017).

Fig. 3 Fourier transform infrared (FTIR) spectra of CCO.

In order to examine the morphology and structures of the prepared samples, Scanning Electron Micrograph (SEM) and transmission electron microscope (TEM) techniques were investigated. Figure $4(a, b)$ shows typical SEM images of the solgel sample. The sample was made up of ultra-fine nanoparticles. These particles displayed some agglomerated morphology because of the nature of the sample. Also, the SEM images of the co-precipitation sample Figure 4 (c, d), show a high rate of porosity. The suspension viscosity plays a significant role in developing the porous structure. With the increase in the viscosity of the suspension, the porous structure becomes compact (Tripathy et al. 2016).

Fig. 4 SEM images of CCO (a, b) sol-gel (c, d) co-precipitation.

The CCO's sol-gel TEM images shown in figure 5 (a) gives clear information regarding the shape and size distribution of the sol-gel nanoparticles. As can be 
seen, this sample was composed of approximately $25 \mathrm{~nm}$ particles on average, which agrees well with $\mathrm{XRD}$ results. However, for the co-precipitation sample, the particle sizes were estimated to be $40 \mathrm{~nm}$ (figure $5 \mathrm{c}$ ). It can be seen from the images that the sol-gel process produced smaller nanoparticles than the co-precipitation method. Moreover, the figures also clearly show that the particle aggregation led to aggregates of an average at the nanometers scale, which was higher for the sol-gel method. Furthermore, the lattice fringe in figures 5 (b and d) corresponded to [121] plane (orientation of the crystallites) of $\mathrm{CuCr}_{2} \mathrm{O}_{4}$ spinel with a diffraction angle $(2 \theta)$ of 35.25 (Mohammad Kabir Hossain 2013). For the two preparation methods, the electron diffraction patterns of the samples were the same due to their structure which was confirmed by the XRD results.

Fig. 5 TEM images of CCO $(a, b)$ sol-gel $(c, d)$ co-precipitation.

Optical properties of CCO samples were measured using the UV-Vis diffuse reflectance spectrum. As shown in figure 6 , the direct bandgap was estimated to be $0.92 \pm 0.1 \mathrm{eV}$ for co-precipitation, and $0.94 \pm 0.1 \mathrm{eV}$ for the sol-gel method, mostly identical and close to the literature values (Lahmar et al. 2012; Akhundi and HabibiYangjeh 2017). The increase of gap energy value in the sol-gel method can be explained by the decrease of the particle size (Wang et al. 2015). Compared to $\mathrm{TiO}_{2}$ and ZnO (Serpone 2006; Miki-yoshida 2016), both methods exhibited excellent absorption ability and can efficiently absorb visible light. Consequently, the rate of formation of electron-hole pairs on the surface of the photocatalyst also greatly increases under visible light irradiation.

Fig. 6 UV-Vis diffuse reflectance spectrum (a) co-precipitation (b) sol-gel.

\subsection{Adsorption performance of $\mathrm{CCO}$}

A set of experiments were carried out by adding $0.1 \mathrm{~g}$ of each catalyst, CCOsg

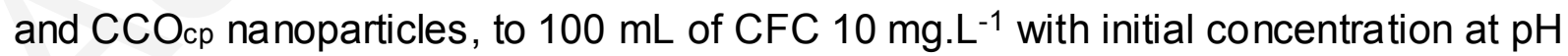
$=6$ and for a contact time $120 \mathrm{~min}$ in darkness (lamp OFF).

Figure 10 depicts the impact of contact time on CFC adsorption onto CCOsG and $\mathrm{CCO}_{\mathrm{cP}}$ nanopowders for two different initial concentrations at $298 \mathrm{~K}$. It can be deduced that the adsorption of CFC varies proportionally with time achieving its optimum adsorption capacities qe within 70 minutes regardless of the adsorbent and initial concentration value. Subsequently, the CFC adsorption remains unchangeable 
with time increment. Therefore, 70 minutes can be considered the appropriate time to obtain equilibrium.

Fig. 7 Equilibrium time for adsorption of CFC (initial concentration:10 and $20 \mathrm{mg} / \mathrm{L}$ ) on both nanomaterials.

The plots in Figure $S 4$ of $\ln \left(q_{e}-q t\right)$ against $t$, display linearity with correlation coefficients $r^{2}$ value, which are generally less than 0.9 in most cases. Besides, the calculated values of $q_{e}$ are by far less than the obtained experimental values (Table 2). Whereas, the pseudo-second-order model plot of $t / q t$ versus time, (Figure S5), shows a better fitting for the data $\left(r^{2}>0.99\right)$. Moreover, $q_{e}$ values calculated from the linear plot of the pseudo-second-order kinetic equation are almost equal to those obtained from the experiments (Table 2). Consequently, it can be confirmed that the CFC adsorption onto CCOsG and CCOCP adsorbent obeys a pseudo-second-order reaction rate.

Table 2 kinetics models parameters for the adsorption of CFC by both nanomaterials.

The intra-particle diffusion kinetic model may govern the adsorption of CFC at the adsorbent surface. From Fig 8, it may be seen that there are two separate stage sorption, i.e., multi-linear in the case of CCOcp adsorbent (Royer et al. 2009; Yazdani et al. 2016). The first straight portion, a sharp one, can be attributed to the transport of CFC across the bulk of the solution to the external surface of CCOCP through the boundary layer, macropore diffusion (Allen et al. 1989). Meanwhile, the second linear portion may mention the final equilibrium where the intraparticle diffusion slowdown owing to the low concentration of CFC, meso- and micropore diffusion (Allen et al. 1989). This leads to the suggestion that the adsorption can follow multiple-sorptionrates. The adsorption of CFC onto CCOsg adsorbent displays only one straight line affirming that the intra-particle diffusion model is the rate-limiting in this case (Fig.S1). The intra-particle diffusion plots are shown in Figure 8, and the main parameters of this model are calculated and listed in Table 3 . The values of intercept $C$ provide information about the thickness of the boundary layer, i.e., the resistance to the external mass transfer. The larger values of the constants shown in Table 3 reflect more significant effects of the solution boundary layer (El-Sikaily et al. 2007; Hameed et al. 2009). 
Fig. 8 Intra-particle diffusion plots for adsorption of CFC (initial concentration:10 and $20 \mathrm{mg} / \mathrm{L}$ ) on both nanomaterials.

Table 3 Intraparticle model parameters for the adsorption of CFC by both nanomaterials.

The adsorption efficiency of CFC differs. As can be shown in Figure 7, adsorption efficiency by $\mathrm{CCO}_{\mathrm{cp}}$ and $\mathrm{CCO}_{\mathrm{sg}}$ catalysts for an initial $10 \mathrm{mg} / \mathrm{L}$ concentration is $58 \%$ and $52 \%$, respectively which shows clearly that $\mathrm{CCO}_{\mathrm{cp}}$ has better adsorption. The same observation for $20 \mathrm{mg} / \mathrm{L}$. The higher adsorption obtained with nanoparticles synthesized via co-precipitation method can be due to the porosity of the sample, in agreement with the SEM images (Figure 5 (c, d)). While The low adsorption in the $\mathrm{CCO}_{\text {sg }}$ sample was less important.

In addition, the advantage of high and rapid adsorption of CFC onto CCOsg and $\mathrm{CCO}_{\mathrm{cp}}$ enhanced the interfacial interactions between CCF and surface catalysts. It is well known that more extrinsic adsorption leads to an increase the photodegradation activities.

\subsection{Photocatalytic performance of $\mathrm{CCO}$}

The photocatalytic activity of $\mathrm{CCO}_{s g}$ and $\mathrm{CCO}_{\mathrm{cp}}$ catalysts was evaluated through the CFC degradation with making ON the lamp. In addition, the test of CFC photolysis was evaluated in the absence of a catalyst using visible light irradiation under the same conditions. the obtained results of photodegradation in Figures 9 and 10 demonstrate the difference between the catalysts and photolysis. As observed, photolysis led to a very low CFC degradation yield, lower than $5 \%$; this can be explained by the low absorption of visible light (Fig S3). On the other hand, in the presence of photocatalyst, the degradation rate of CFC reached $57 \%$ within 4 hours for the $\mathrm{CCO}_{s g}$, while it was lower for the $\mathrm{CCO}_{c p}$ catalyst $49 \%$. This difference can be due to the ultrafine nature of the sol-gel nanoparticles, which gives a higher specific surface area as confirmed by the characterization.

Fig. 9 Equilibrium time for photodegradation of CFC (initial concentration: $20 \mathrm{mg} / \mathrm{L}$ ) on both nanomaterials.

Fig. 10 Kinetic UV photocatalytic degradation of CFC with both nanomaterials CCOsG and CCOcP.

The kinetics results of photocatalytic degradation under visible irradiation are illustrated in Figures 9 and 10. According to the regression coefficient, mainly greater 
than 0.98 , the experimental results are well simulated by the Lagergren pseudo-firstorder model for both tested adsorbents. The obtained apparent rate constants, $k$ deg, and $r^{2}$ values, obtained from the plot of $C_{t} / C_{0}$ against $t$, are assembled in Table 4. As can be noted, in Fig. 10 photolysis does not affect the degradation of CFC, but the presence of the photocatalyst reduces extremely the concentration of CFC.

Table 4 Intraparticle and Lagergren pseudo-first-order model constants for the photodegradation of CFC by both nanomaterial SG and CP.

The photodegradation of CFC at the surface of the adsorbent may be governed by the intraparticle diffusion kinetic model, since, $q t$ and $t^{1 / 2}$ convene a linear correlation (Fig. S6). Besides, the regression coefficient values are higher than 0.96, denoting the relevance of the data in the model. The intra-particle diffusion plots show that the main parameters of this model are calculated and collected in Table 4. The thickness of the boundary layer is strongly correlated to the intercept values. The larger intercept of the graph ( $C$ value, Table 4 ) indicates a more significant boundary layer effect.

In Fig. S.6, trend lines are plotted and do not pass through the origin. This observation can be ascribed to some level of boundary layer control. Such behavior is an indication that the intra-particle diffusion is not the sole rate-controlling step, as other kinetic processes may influence the photodegradation rate. In other words, all of these operations are operating concurrently and cannot be neglected (Royer et al. 2009; Yazdani et al. 2016).

The mass transfer kinetic model constants are obtained from the slope and the intercept of the straight line of $\mathrm{Ln}\left(\mathrm{C}_{0}-\mathrm{C}_{t}\right)$ versus time (Fig. S7 and S8). However, no linear relation was observed, and the regression coefficient is mainly very low and never exceeds 0.82 . This result indicates that the uptake and photodegradation rate is not governed by mass transfer through a liquid film boundary, i.e., the convective mass transfer.

The photodegradation of organic compounds by a catalyst semi-conductor can be ascribed to different reaction pathways regulated by different active species such as $\mathrm{OH}^{\circ}, \mathrm{O}_{2}{ }^{\circ}$, and holes $\left(\mathrm{h}^{+}\right)$(Zuo et al. 2017). The energy band structure is a key factor that may affect the photocatalytic activity (Lahmar et al. 2017). UV-Vis was 
used to analyze the optical properties of the catalysts and to deduce its forbidden bandwidth. CCO's clearly displayed a $0.9 \mathrm{eV}$ bandgap energy (Fig. 9).

When photocatalytic reactions occur in an aqueous solution, the holes are effectively broken by water and generate hydroxyl radicals $\mathrm{OH}^{\cdot}$ (Kumar et al. 2020). In our previous works (Belaissa et al. 2016; Abou Dalle et al. 2017; Aboudalle et al. 2018; Zadi et al. 2018), it was proposed that both holes and hydroxyl radicals are involved as oxidizing agents responsible for CFC degradation. The basic process is illustrated in Fig. S9 and equations 1 to 5 suggest the following photodegradation mechanism under visible light irradiation:

$\mathrm{CuCr}_{2} \mathrm{O}_{4}+\mathrm{hv} \rightarrow \mathrm{CuCr}_{2} \mathrm{O}_{4}{ }^{*}+e^{-}+h^{+}$

$\mathrm{H}_{2} \mathrm{O}+h^{+} \rightarrow \mathrm{OH}^{*}+\mathrm{H}^{+}$

$\mathrm{O}_{2}+e^{-} \rightarrow \mathrm{O}_{2}^{-*}$

$\mathrm{CFC}+\mathrm{O}_{2}^{-*}$ or $\mathrm{OH}^{*} \rightarrow \mathrm{CO}_{2}+\mathrm{H}_{2} \mathrm{O}+$ small intermediate by - products

$C F C+h v \rightarrow C F C^{*}$

\section{Conclusion}

In the present work, CCO nanoparticles were successfully synthesized using co-precipitation and sol-gel methods. The catalysts were then characterized using several techniques to distinguish the effect of each synthesizing process. The XRD with Rietveld refinement, BET, SEM, and TEM confirmed that synthesized CCO via the sol-gel method has the smallest particle size. Moreover, its BET surface area was found to be higher than that achieved by the co-precipitation method, which suggests a higher photocatalysis activity. It should be noticed that the co-precipitation method gave a higher rate of porosity to the catalyst, leading to excellent adsorption property. Those characterizations were demonstrated using CFC as a target antibiotic example for testing the adsorption and photocatalytic performance of $\mathrm{CCO}$.

The kinetics of the adsorption process was found to obey the pseudo-secondorder law for both tested adsorbents. However, the Lagergren first-order model fits well with photodegradation experimental data. Whereas, the intra-particle diffusion model gave two distinct regions in the case of CFC adsorption by COCCP nanomaterial, i.e., a fast diffusion at the solution boundary film followed by slow intraparticle diffusion. The CFC adsorption occurs in one stage in the case of COCsG. 
Similarly, the photodegradation process occurs in one step without passing through the origin, suggesting that the rate is not only controlled by the intra-particle diffusion process, particularly at its initial phase.

The adsorption and photocatalytic results showed that the catalyst synthesis method is a crucial parameter regarding the catalyst properties, such as particle size and morphology which can change the catalyst activity, as we noticed that SG has more photocatalytic activity. On the other hand, CP has a higher adsorption activity. Furthermore, this study showed that the CCO spinel might be an effective candidate for the treatment of other organic pollutants present in wastewater.

\section{Declaration}

\section{Ethics approval and consent to participate}

Not applicable

\section{Consent for publication}

Not applicable

\section{Competing interest}

The authors declare that they have no conflict of interest.

\section{Authors contributions}

Oussama Baaloudj and Mohamed Kebir: investigation, formal analysis, visualization, writing original draft.

Noureddine Nasrallah and Aymen Amin Assadi: conceptualization, funding acquisition, methodology, resources, project administration, supervision, writingreview and editing.

Lotfi Khezami: writing-review and expriment modeling and simulation Abdeltif Amrane: investigation, visualization.

\section{Availability of data and materials:}

The datasets used and/or analysed during the current study are available from the corresponding author on reasonable request. 


\section{Acknowledgment}

The authors gratefully acknowledge the financial support from the Thematic Research Agency for Science and Technology (ATRST) through the national research program (PM 04/2018, PRFU Project NB00L01UN180120190003) and the Directorate-General for Scientific Research and Technological Development (DGRSDT) of Algeria.

\section{References}

Abou Dalle A, Domergue L, Fourcade F, et al (2017) Efficiency of DMSO as hydroxyl radical probe in an Electrochemical Advanced Oxidation Process - Reactive oxygen species monitoring and impact of the current density. Electrochim Acta 246:1-8. https://doi.org/10.1016/j.electacta.2017.06.024

Aboudalle A, Fourcade F, Assadi AA, et al (2018) Reactive oxygen and iron species monitoring to investigate the electro-Fenton performances. Impact of the electrochemical process on the biodegradability of metronidazole and its byproducts. Chemosphere 199:486-494. https://doi.org/10.1016/j.chemosphere.2018.02.075

Acharyya SS, Ghosh S, Adak S, et al (2015) Fabrication of CuCr2O4 spinel nanoparticles: A potential catalyst for the selective oxidation of cycloalkanes via activation of Csp3-H bond. Catal Commun 59:145-150. https://doi.org/10.1016/j.catcom.2014.10.015

Aissani T, Yahiaoui I, Boudrahem F, et al (2020) Sulfamethazine degradation by heterogeneous photocatalysis with $\mathrm{ZnO}$ immobilized on a glass plate using the heat attachment method and its impact on the biodegradability. React Kinet Mech Catal 131:471-487. https://doi.org/10.1007/s11144-020-01842-4

Aissani T, Yahiaoui I, Boudrahem F, et al (2018) The combination of photocatalysis process (UV/TiO2(P25) and UV/ZnO) with activated sludge culture for the degradation of sulfamethazine. Sep Sci Technol 53:1423-1433. https://doi.org/10.1080/01496395.2018.1445109

Akhtar MN, Babar M, Qamar S, et al (2019) Structural Rietveld refinement and 
magnetic features of prosademium ( $\mathrm{Pr}$ ) doped Cu nanocrystalline spinel ferrites. Ceram Int 45:10187-10195. https://doi.org/10.1016/j.ceramint.2019.02.069

Akhundi A, Habibi-Yangjeh A (2017) Graphitic carbon nitride nanosheets decorated with $\mathrm{CuCr} 2 \mathrm{O} 4$ nanoparticles: Novel photocatalysts with high performances in visible light degradation of water pollutants. J Colloid Interface Sci 504:697-710. https://doi.org/10.1016/j.jcis.2017.06.025

Allen SJ, McKay G, Khader KYH (1989) Intraparticle diffusion of a basic dye during adsorption onto sphagnum peat. Environ Pollut 56:39-50. https://doi.org/10.1016/0269-7491(89)90120-6

Belaissa Y, Nibou D, Assadi AA, et al (2016) A new hetero-junction p-CuO/n-ZnO for the removal of amoxicillin by photocatalysis under solar irradiation. J Taiwan Inst Chem Eng 68:254-265. https://doi.org/10.1016/j.jtice.2016.09.002

Bykkam S, Ahmadipour M, Narisngam S (2015) Extensive Studies on X-Ray Diffraction of Green Synthesized Silver Nanoparticles. 1-10

Chen WR, Huang $\mathrm{CH}$ (2010) Adsorption and transformation of tetracycline antibiotics with aluminum oxide. Chemosphere 79:779-785. https://doi.org/10.1016/j.chemosphere.2010.03.020

Das AK, Govindaraj R, Srinivasan A (2018) Structural and magnetic properties of solgel derived $\mathrm{CaFe} 2 \mathrm{O} 4$ nanoparticles. J Magn Magn Mater 451:526-531. https://doi.org/10.1016/j.jmmm.2017.11.102

Devi PS, Lee Y, Margolis J, et al (2002) Comparison of citrate-nitrate gel combustion and precursor plasma spray processes for the synthesis of yttrium aluminum garnet. J Mater Res 17:2846-2851. https://doi.org/10.1557/JMR.2002.0413

Dollase WA, O'Neill HSC (1997) The spinels CuCr2O4 and CuRh2O4. Acta Crystallogr Sect C Cryst Struct Commun 53:657-659. https://doi.org/10.1107/S0108270197000486

El-Sikaily A, Nemr A El, Khaled A, Abdelwehab O (2007) Removal of toxic chromium from wastewater using green alga Ulva lactuca and its activated carbon. $\mathrm{J}$ Hazard Mater 148:216-228. https://doi.org/10.1016/j.jhazmat.2007.01.146 
from aqueous solution by graphene oxide. J Colloid Interface Sci 368:540-546. https://doi.org/10.1016/j.jcis.2011.11.015

Geng Q, Zhao X, Gao X, et al (2012) Low-temperature combustion synthesis of $\mathrm{CuCr}$ $2 \mathrm{O} 4$ spinel powder for spectrally selective paints. J Sol-Gel Sci Technol 61:281288. https://doi.org/10.1007/s10971-011-2625-2

Giannopoulou I, Saïs F, Thomopoulos R (2015) Handbook-of-pharmaceuticalexcipients-6th-edition. Rev des Nouv Technol I'Information E.28:257-262

Hameed BH, Salman JM, Ahmad AL (2009) Adsorption isotherm and kinetic modeling of 2,4-D pesticide on activated carbon derived from date stones. $\mathrm{J}$ Hazard Mater 163:121-126. https://doi.org/10.1016/j.jhazmat.2008.06.069

Hariganesh S, Vadivel S, Maruthamani D, et al (2020) Facile large scale synthesis of $\mathrm{CuCr2O4/CuO} \mathrm{nanocomposite} \mathrm{using} \mathrm{MOF} \mathrm{route} \mathrm{for} \mathrm{photocatalytic} \mathrm{degradation}$ of methylene blue and tetracycline under visible light. Appl Organomet Chem 34:1-10. https://doi.org/10.1002/aoc.5365

Hou J, Chen Z, Gao J, et al (2019) Simultaneous removal of antibiotics and antibiotic resistance genes from pharmaceutical wastewater using the combinations of upflow anaerobic sludge bed, anoxic-oxic tank, and advanced oxidation technologies. Water Res 159:511-520. https://doi.org/10.1016/j.watres.2019.05.034

Hu Z, Qin Y, Zhou H, et al (2011) Preparation and photoelectric properties of CuCr2O4 nanopowders. Adv Mater Res 284-286:974-979. https://doi.org/10.4028/www.scientific.net/AMR.284-286.974

Ikhlef-Taguelmimt T, Hamiche A, Yahiaoui I, et al (2020) Tetracycline hydrochloride degradation by heterogeneous photocatalysis using TiO2(P25) immobilized in biopolymer (chitosan) under UV irradiation. Water Sci Technol 2:1-9. https://doi.org/10.2166/wst.2020.432

Kaczala F, E. Blum S (2015) The Occurrence of Veterinary Pharmaceuticals in the Environment: A Review. Curr Anal Chem 12:169-182. https://doi.org/10.2174/1573411012666151009193108

Kadji H, Yahiaoui I, Garti Z, et al (2020) Kinetic degradation of amoxicillin by using 
the electro-Fenton process in the presence of a graphite rods from used batteries. Chinese J Chem Eng. https://doi.org/10.1016/j.cjche.2020.08.032

Kafshgari LA, Ghorbani M, Azizi A (2019) Synthesis and characterization of manganese ferrite nanostructure by co-precipitation, sol-gel, and hydrothermal methods. Part Sci Technol 37:900-906. https://doi.org/10.1080/02726351.2018.1461154

Kamagate M, Amin Assadi A, Kone T, et al (2018) Activation of persulfate by irradiated laterite for removal of fluoroquinolones in multi-component systems. J Hazard Mater 346:159-166. https://doi.org/10.1016/j.jhazmat.2017.12.011

Kenfoud H, Nasrallah N, Baaloudj O, et al (2020) Photocatalytic reduction of Cr(VI) onto the spinel $\mathrm{CaFe} 2 \mathrm{O} 4$ nanoparticles. Optik (Stuttg) 223:165610. https://doi.org/10.1016/j.ijleo.2020.165610

Kumar R, Barakat MA, Al-Mur BA, et al (2020) Photocatalytic degradation of cefoxitin sodium antibiotic using novel BN/CdAl2O4 composite. J Clean Prod 246:119076. https://doi.org/10.1016/j.jclepro.2019.119076

Kümmerer K (2009) Antibiotics in the aquatic environment - A review - Part II. Chemosphere 75:435-441. https://doi.org/10.1016/j.chemosphere.2008.12.006

Lahmar H, Benamira M, Akika FZ, Trari M (2017) Reduction of chromium (VI) on the hetero-system CuBi2O4/TiO2 under solar light. J Phys Chem Solids 110:254259. https://doi.org/10.1016/j.jpcs.2017.06.021

Lahmar H, Kebir M, Nasrallah N, Trari M (2012) Photocatalytic reduction of $\mathrm{Cr}(\mathrm{VI})$ on the new hetero-system CuCr2O 4/ZnO. J Mol Catal A Chem 353-354:74-79. https://doi.org/10.1016/j.molcata.2011.10.026

Lalouckova K, Skrivanova E (2019) Antibiotic Resistance in Livestock Breeding: A Review. Sci Agric Bohem 50:15-22. https://doi.org/10.2478/sab-2019-0003

Li B, Zhang T (2010) Biodegradation and adsorption of antibiotics in the activated sludge process. Environ Sci Technol 44:3468-3473. https://doi.org/10.1021/es903490h

Lou W, Kane A, Wolbert D, et al (2017) Study of a photocatalytic process for removal of antibiotics from wastewater in a falling film photoreactor: Scavenger study and 
process intensification feasibility. Chem Eng Process Process Intensif 122:213221. https://doi.org/10.1016/j.cep.2017.10.010

Mbadcam JK, Anagho SG, Nsami JNDI, Kammegne AM (2011) Kinetic and equilibrium studies of the adsorption of lead ( II ) ions from aqueous solution onto two Cameroon clays: Kaolinite and smectite. J Environ Chem Ecotoxicol 3:290297

Miki-yoshida M (2016) Optical Band Gap Estimation of ZnO Nanorods a E = B ^ E Eg h. 19:33-38. https://doi.org/10.1590/1980-5373-mr-2015-0612

Mobini S, Meshkani F, Rezaei M (2017) Surfactant-assisted hydrothermal synthesis of $\mathrm{CuCr} 2 \mathrm{O} 4$ spinel catalyst and its application in $\mathrm{CO}$ oxidation process. J Environ Chem Eng 5:4906-4916. https://doi.org/10.1016/j.jece.2017.09.027

Mohammad Kabir Hossain (2013) Copper-based ternary oxide semiconductors for solar energy conversion and environmental remediation. J Chem Inf Model 53:1689-1699. https://doi.org/10.1017/CBO9781107415324.004

Mostafaloo R, Mahmoudian MH, Asadi-ghalhari M (2019) BiFeO 3 / Magnetic nanocomposites for the photocatalytic degradation of ce fi xime from aqueous solutions under visible light. J Photochem Photobiol A Chem 382:111926. https://doi.org/10.1016/j.jphotochem.2019.111926

Paul B, Bhuyan B, Purkayastha DD, et al (2015) Facile synthesis of spinel CuCr2O4 nanoparticles and studies of their photocatalytic activity in degradation of some selected organic dyes. J Alloys Compd 648:629-635. https://doi.org/10.1016/j.jallcom.2015.07.012

Peymanfar R, Ramezanalizadeh H (2018) Sol-gel assisted synthesis of CuCr2O4 nanoparticles: An efficient visible-light driven photocatalyst for the degradation of water pollutions. Optik (Stuttg) 169:424-431. https://doi.org/10.1016/j.ijleo.2018.05.072

Ramanujam P, Vaidhyanathan B, Binner J, et al (2014) A comparative study of the synthesis of nanocrystalline Yttrium Aluminium Garnet using sol-gel and coprecipitation methods. Ceram Int 40:4179-4186. https://doi.org/10.1016/j.ceramint.2013.08.075 
Ramezanalizadeh H, Peymanfar R, Khodamoradipoor N (2019) Design and development of a novel lanthanum inserted $\mathrm{CuCr} 2 \mathrm{O} 4$ nanoparticles photocatalyst for the efficient removal of water pollutions. Optik (Stuttg) 180:113124. https://doi.org/10.1016/j.jjleo.2018.11.067

Royer B, Cardoso NF, Lima EC, et al (2009) Applications of Brazilian pine-fruit shell in natural and carbonized forms as adsorbents to removal of methylene blue from aqueous solutions-Kinetic and equilibrium study. J Hazard Mater 164:12131222. https://doi.org/10.1016/j.jhazmat.2008.09.028

S Lagergren, S LAGERGREN, S.Y. Lagergren, SY Lagergren KS (1898) Zurtheorie der sogenannten adsorption gel sterstoffe. Bih till K Sven Vet-Akad Handl 24(4):1-39

Santhanam R, Rambabu B (2010) High rate cycling performance of Li1.05Ni1/3Co1/3Mn1/3O2 materials prepared by sol-gel and co-precipitation methods for lithium-ion batteries. J Power Sources 195:4313-4317. https://doi.org/10.1016/j.jpowsour.2010.01.016

Serpone N (2006) Is the band gap of pristine TiO2 narrowed by anion- and cationdoping of titanium dioxide in second-generation photocatalysts? J Phys Chem B 110:24287-24293. https://doi.org/10.1021/jp065659r

Shan R, Lu L, Gu J, et al (2020) Photocatalytic degradation of methyl orange by $\mathrm{Ag} / \mathrm{TiO} /$ /biochar composite catalysts in aqueous solutions. Mater Sci Semicond Process 114:105088. https://doi.org/10.1016/j.mssp.2020.105088

Shooshtari NM, Ghazi MM (2017) An investigation of the photocatalytic activity of nano A-Fe2O3/ZnO on the photodegradation of cefixime trihydrate. Chem Eng J 315:527-536. https://doi.org/10.1016/j.cej.2017.01.058

Tripathy S, Saini DS, Bhattacharya D (2016) Synthesis and fabrication of MgAl 204 ceramic foam via a simple, low-cost and eco-friendly method. J Asian Ceram Soc 4:149-154. https://doi.org/10.1016/j.jascer.2016.01.008

Villars P, Cenzual K (eds) CuCr2O4 Crystal Structure: Datasheet from “PAULING FILE Multinaries Edition -- 2012" in SpringerMaterials (https://materials.springer.com/isp/crystallographic/docs/sd_0309081) 
Wang SF, Sun GZ, Fang LM, et al (2015) A comparative study of ZnAl2O4 nanoparticles synthesized from different aluminum salts for use as fluorescence materials. Sci Rep 5:1-12. https://doi.org/10.1038/srep12849

Y.S. Ho GM (1999) Pseudo-second order model for sorption processes. Process Biochem 34 451-465. https://doi.org/10.1021/acs.oprd.7b00090

Y.S. Ho GM (1998) Sorption of dye from aqueous solution by peat. Chem Eng J 70 $115-124$

Yahiaoui I, Yahia Cherif L, Madi K, et al (2018) The feasibility of combining an electrochemical treatment on a carbon felt electrode and a biological treatment for the degradation of tetracycline and tylosin-application of the experimental design methodology. Sep Sci Technol 53:337-348. https://doi.org/10.1080/01496395.2017.1385626

Yazdani MR, Tuutijärvi T, Bhatnagar A, Vahala R (2016) Adsorptive removal of arsenic $(V)$ from aqueous phase by feldspars: Kinetics, mechanism, and thermodynamic aspects of adsorption. J Mol Liq 214:149-156. https://doi.org/10.1016/j.molliq.2015.12.002

YE, Zuo-Guang et al Single crystal growth, structure refinement, ferroelastic domains and phase transitions of the hausmannite $\mathrm{CuCr} 2 \mathrm{O} 4$. Ferroelectrics 162:103-118

Zadi T, Assadi AA, Nasrallah N, et al (2018) Treatment of hospital indoor air by a hybrid system of combined plasma with photocatalysis: Case of trichloromethane. Chem Eng J 349:276-286. https://doi.org/10.1016/j.cej.2018.05.073

Zhu XD, Wang YJ, Sun RJ, Zhou DM (2013) Photocatalytic degradation of tetracycline in aqueous solution by nanosized $\mathrm{TiO}$. Chemosphere 92:925-932. https://doi.org/10.1016/j.chemosphere.2013.02.066

Zuo S, Chen Y, Liu W, et al (2017) A facile and novel construction of attapulgite/Cu2O/Cu/g-C3N4 with enhanced photocatalytic activity for antibiotic degradation. Ceram Int 43:3324-3329. https://doi.org/10.1016/j.ceramint.2016.11.173 


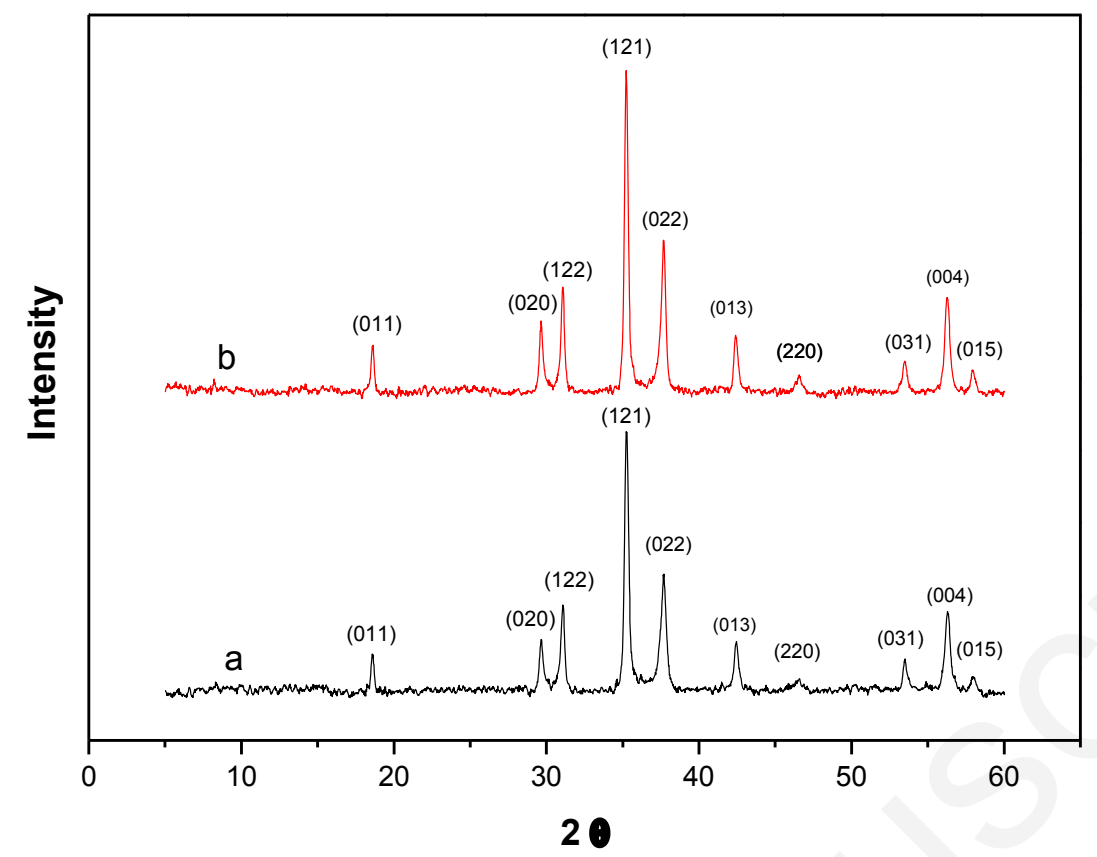

Fig. 1 XRD diffractogram of CCO (a) co-precipitation (b) sol-gel.

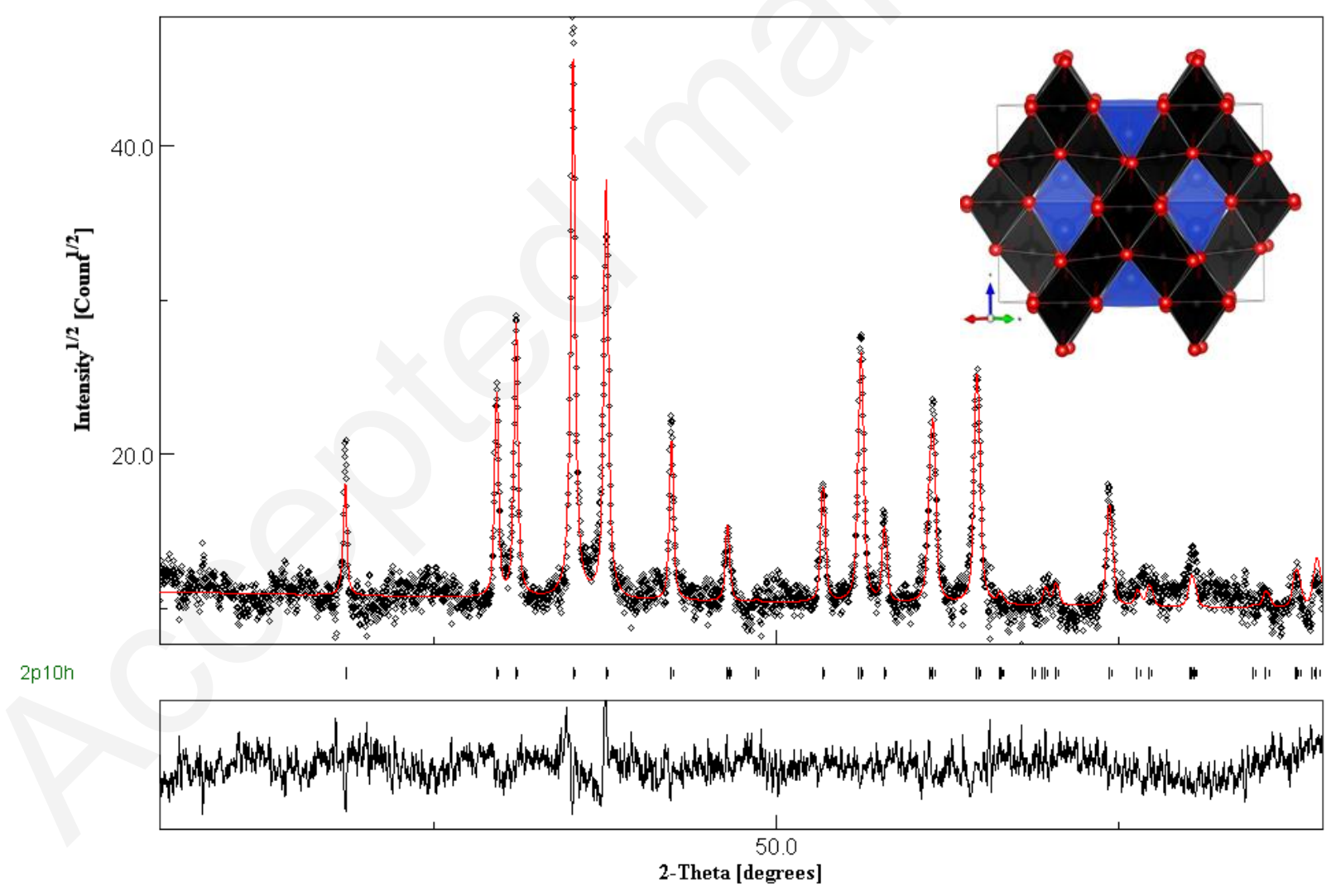

Fig. 2 Reitveld refined XRD diffractogram. Inset: the structural representation of CCO. 


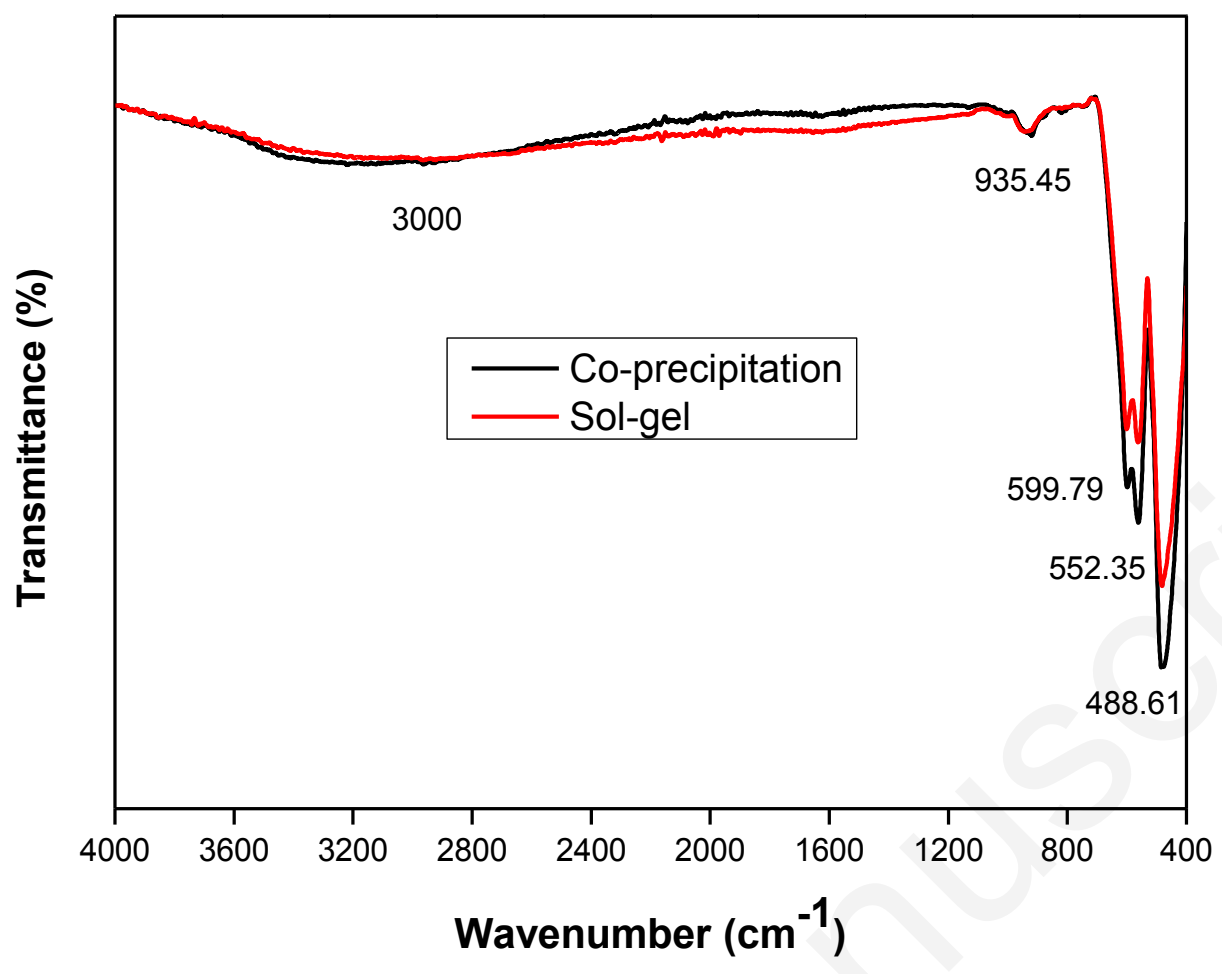

Fig. 3 Fourier transform infrared (FTIR) spectra of CCO.
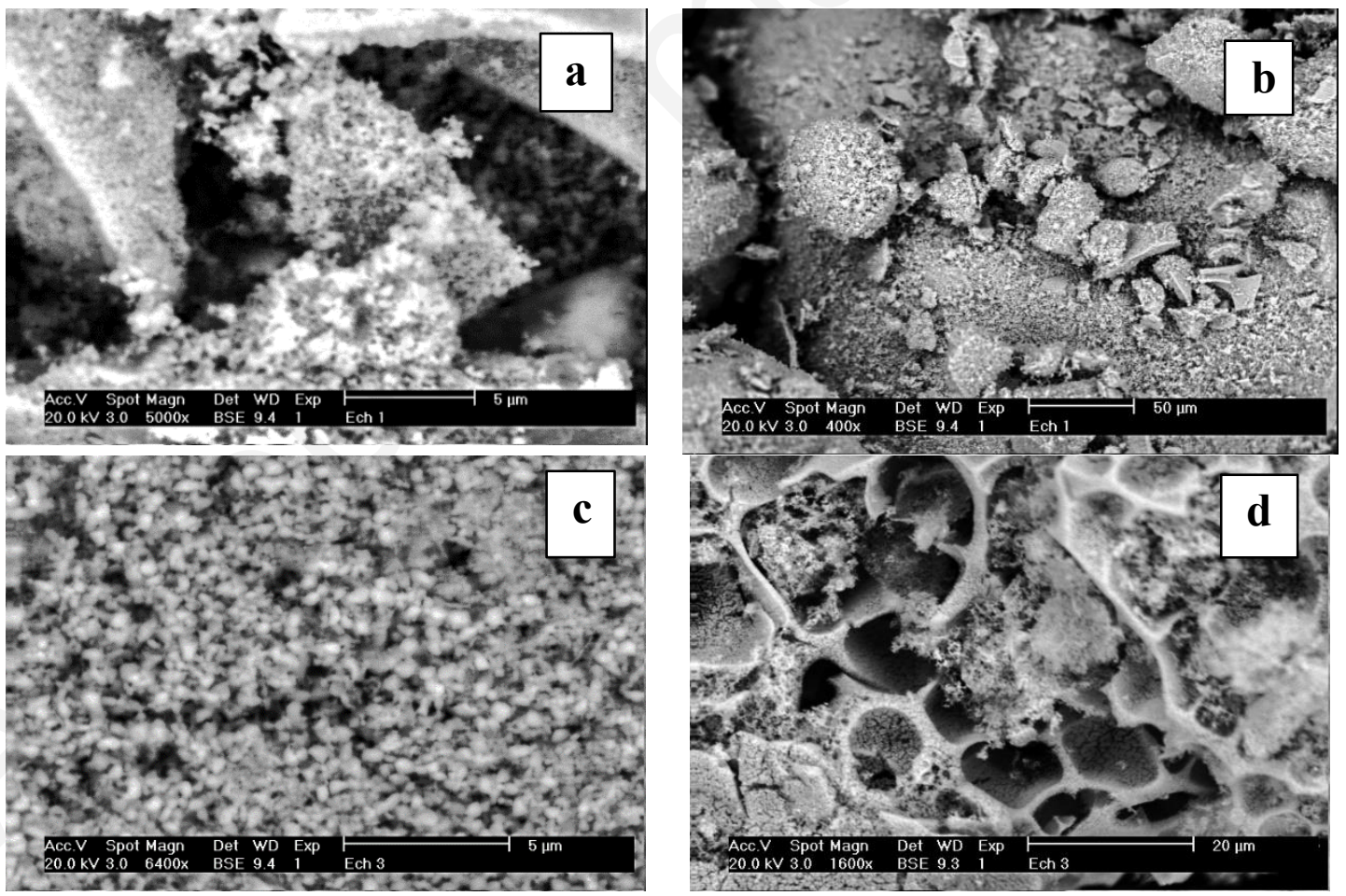

Fig. 4 SEM images of CCO $(a, b)$ sol-gel $(c, d)$ co-precipitation. 


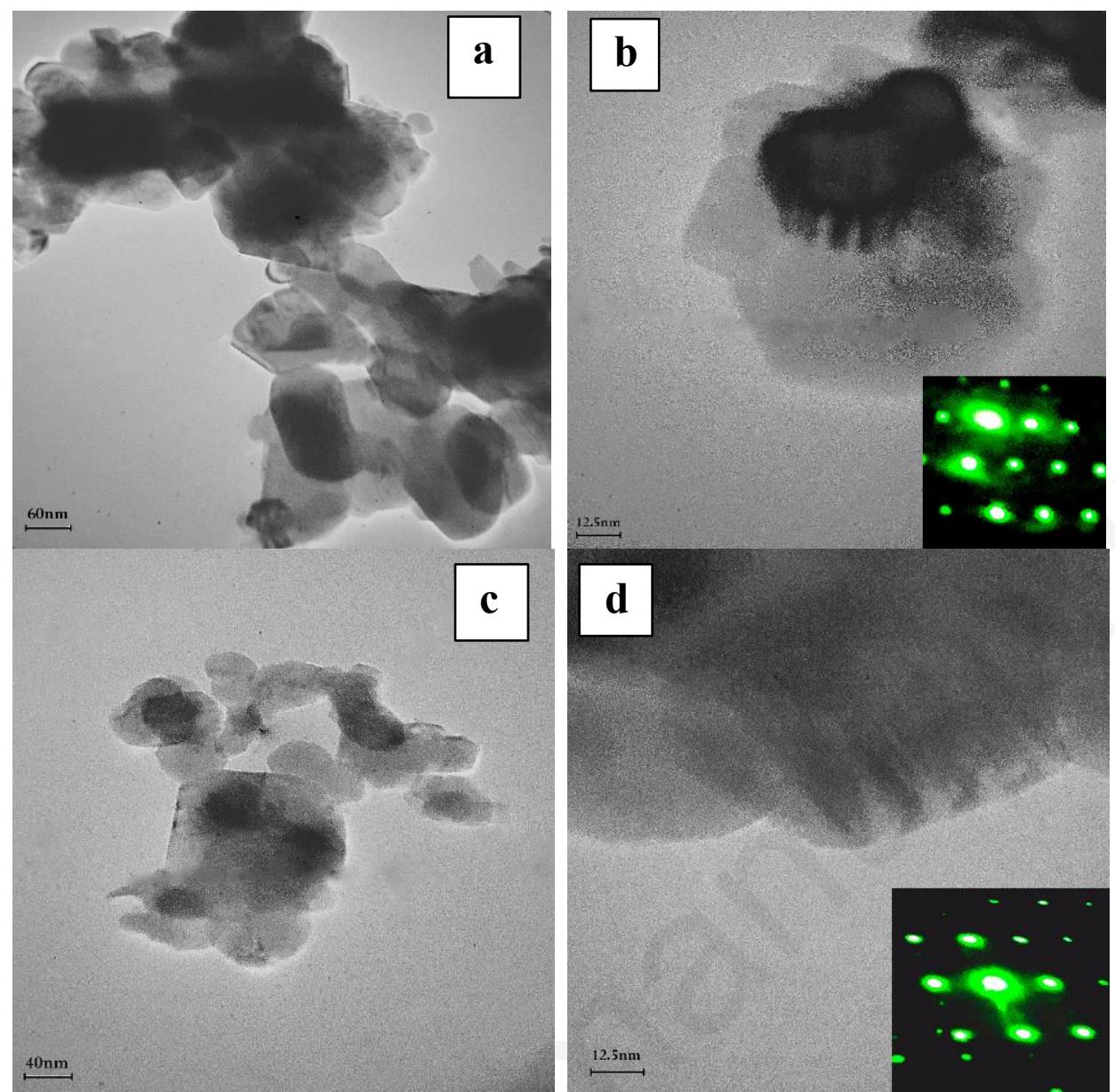

Fig. 5 TEM images of CCO (a,b) sol-gel (c,d) co-precipitation.
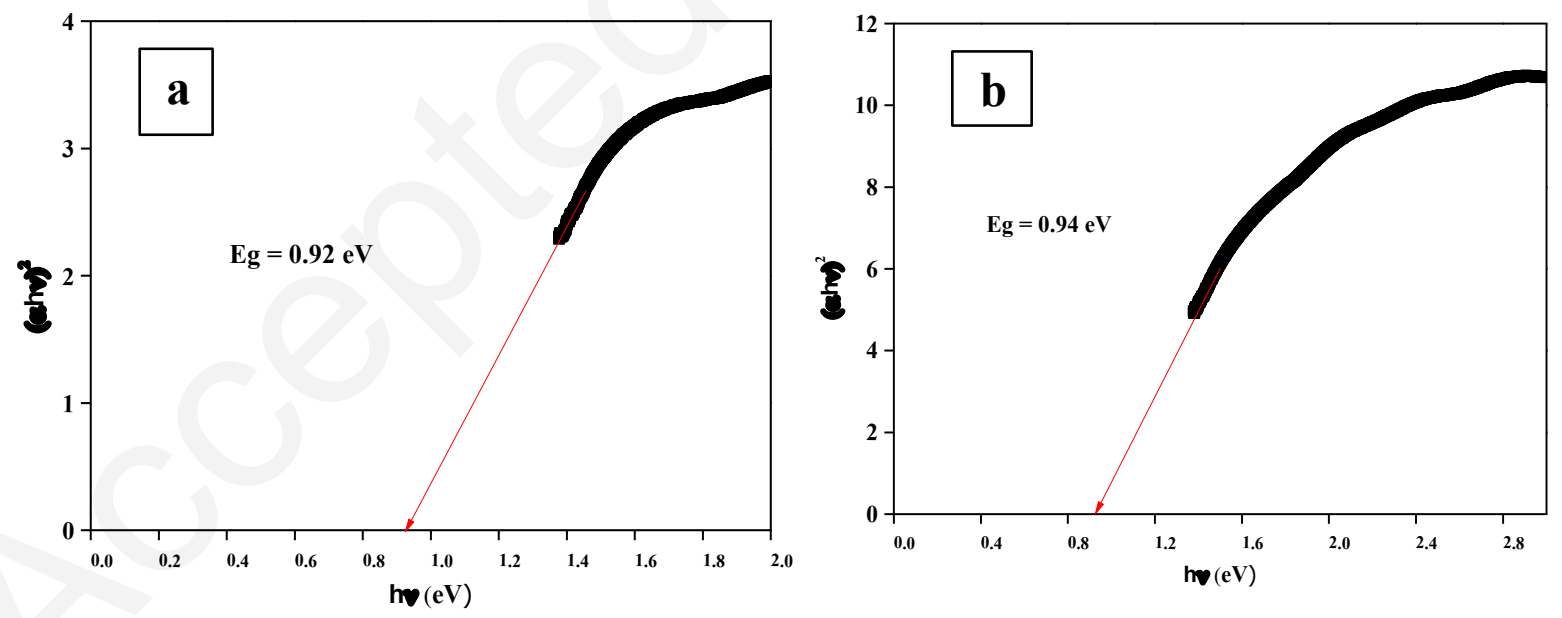

Fig. $6 \mathrm{UV}-\mathrm{Vis}$ diffuse reflectance spectrum (a) co-precipitation (b) sol-gel. 


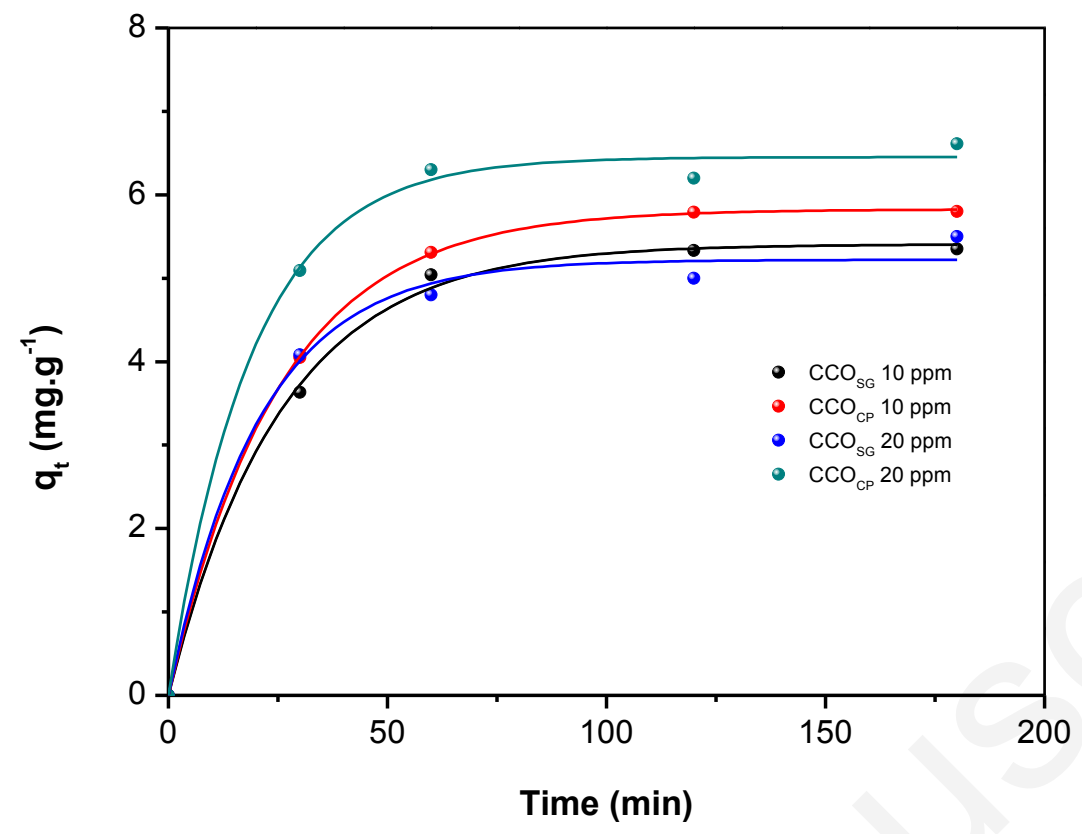

Fig. 7 Equilibrium time for adsorption of CFC (initial concentration:10 and $20 \mathrm{mg} / \mathrm{L}$ ) on both nanomaterials.

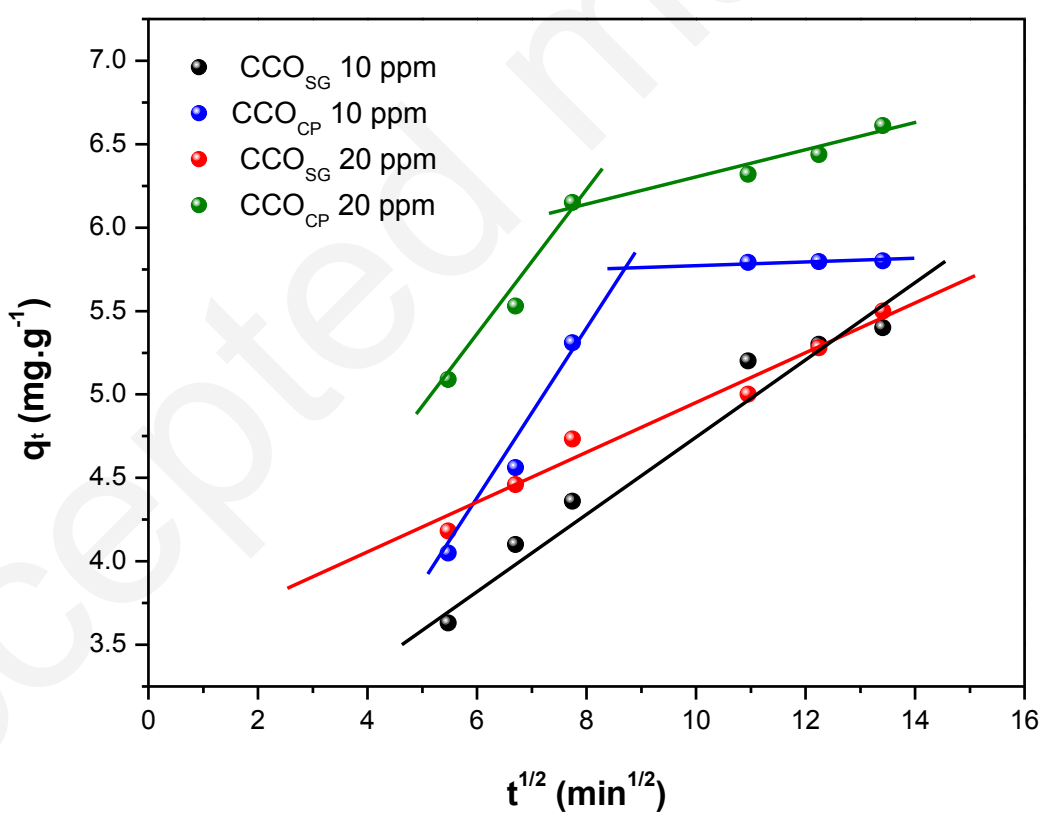

Fig. 8 Intra-particle diffusion plots for adsorption of CFC (initial concentration:10 and $20 \mathrm{mg} / \mathrm{L}$ ) on both nanomaterials. 


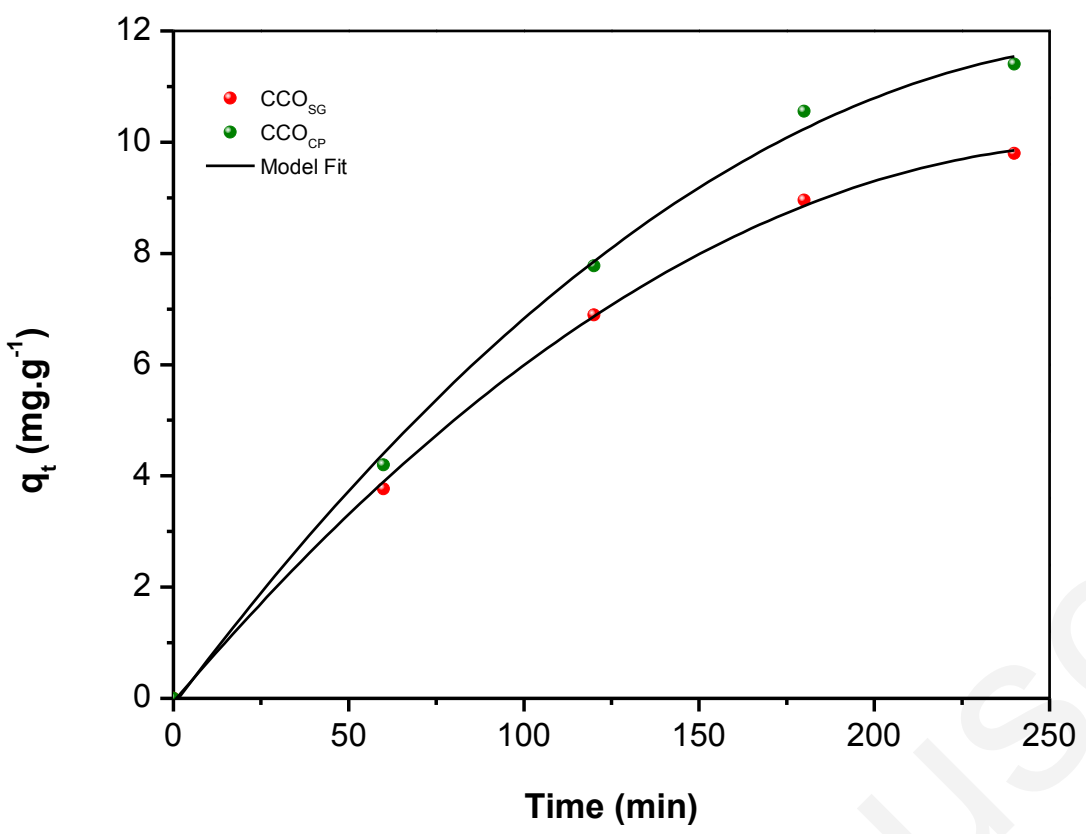

Fig. 9 Equilibrium time for photodegradation of CFC (initial concentration: $20 \mathrm{mg} / \mathrm{L}$ ) on both nanomaterials.

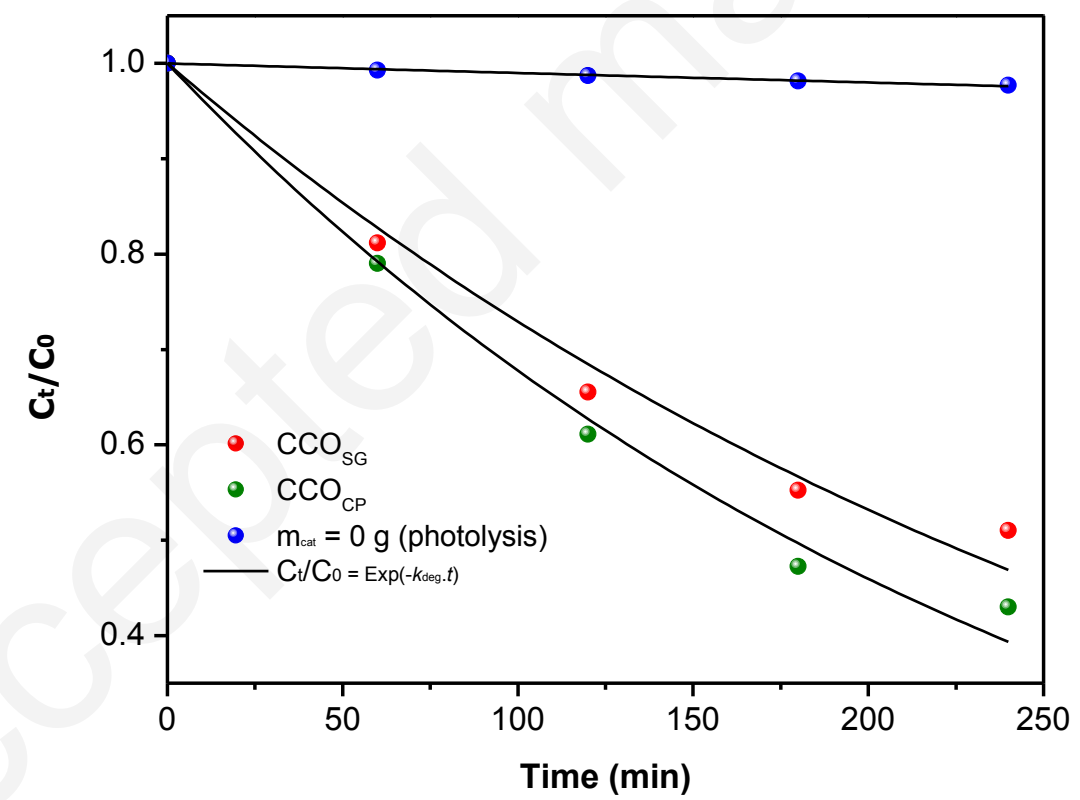

Fig. 10 Kinetic UV photocatalytic degradation of CFC with both nanomaterials $\mathrm{CCO}_{\mathrm{SG}}$ and $\mathrm{CCO}_{\mathrm{CP}}$. 